\title{
Dynamic behaviour of a steel plate girder railroad bridge with rail joints
}

\author{
H. M. Kim ${ }^{1}$, S. I. Kim ${ }^{2}$ \& W. S. Hwang ${ }^{2}$ \\ ${ }^{1}$ Department of Railroad Structure Research, \\ Korea Railroad Research Institute, Korea \\ ${ }^{2}$ Department of Civil and Environmental Engineering, \\ Inha University, Korea
}

\begin{abstract}
This study investigates the effects of rail joints on the dynamic behaviour of railroad bridges through a dynamic experiment. The subject bridge is a typical steel plate girder railroad bridge. The bridge is $53.4 \mathrm{~m}$ long, and consists of four simply supported spans (4@12.10m). Rail joints are positioned in the third span. It is $1.8 \mathrm{~m}$ away from the starting point of the third span. The regular service train applied the dynamic loading. The test train is composed of one diesel locomotive and seven passenger carriages, which is commonly running on the existing railroad lines in Korea. The range of measured speed is from 19.1 to $124.0 \mathrm{~km} / \mathrm{hr}$. Accelerometers are installed at the bottom flange of the centre of the third span to acquire a bridge response caused by the rail joint. For comparison, another accelerometer is installed at the same position of the first span, which has no rail joint. From the measured results, Peak vale (PV), root mean square (RMS) and dynamic amplification factor (DAF) value analysis are performed in order to compare the instantaneous maximum and mean amplitude of acceleration at each span. The result shows a significant increase in the acceleration of the span with joints. In addition, DAF is from 0.22 to 1.92 for the measured speed zone. The result also shows that rail joints on a bridge produce an impact effect. Thus, it increases the dynamic response of the bridge and deteriorates ride comfort.
\end{abstract}

Keywords: rail joint, acceleration, impact load, dynamic amplified factor, steel plate girder railroad bridge. 


\section{Introduction}

The dynamic behaviour of a railroad bridge is affected by not only the interaction between the bridge and track, but also the interaction between the train and the track. This is because train running along the fixed path of the track changes according to the condition of the contact surface. The irregularity of the track surface produces dynamic load. In this condition, the variation of dynamic load is large. In particular, defects or rail joints on the track with discontinuous contact surface results in considerable high impact load. The calculation methods of dynamic load caused by defective tracks have been studied by Jenkins [1] and Alias [2]. However, there are insufficient empirical data on what direct effects rail joints have on the behaviour of the bridge. In order to prevent discontinuous operating conditions caused by rail joints, most high-speed railroads adopt continuous welded rail (CWR). However, many existing bridges using standardlength rails (SLR) have rail joints on them. The steel plate girder bridge is a typical structure of short-span, high-strength and high-frequency bridges. It is commonly connected to sleepers without ballast. So, it is most vulnerable to acceleration.

The present study measured the vertical acceleration of bridges with joints and those without in steel plate girder bridges, and examined the effect of rail joints on the dynamic response of bridges through analyzing the PV, RMS and DAF values from measured acceleration.

\section{General theory of impact load caused by a rail joint}

Rail joints that have a geometrically discontinuous section with the adjoining rail are largely divided into upward bump, downward bump, joint gap and bump with a break. Depending on the form of discontinuity, the pattern of impact increase is different. It is known that impact from speed is high in order of upward bump and bump with a break, and in these forms of discontinuity impact is proportional to speed. In downward bump and joint gap, however, impact does not increase along with the rise of speed.

Impact load consist of a short-time peak (P1 load) and a delayed peak (P2 load). The short time peak is associated with battering of the rail-end corner by the unsprung mass of the wheel set. The delayed peak is associated with rail bending, which is a more resilient deformation mode than corner batter. Each force is described by the following equations, as given by Jenkins [1].

$$
\begin{gathered}
P_{1}=P_{0}+2 \alpha v \frac{\sqrt{k_{H} m_{T 1}}}{\sqrt{1+m_{T 1} / m_{u}}} \\
P_{2}=P_{0}+2 \alpha v \frac{\sqrt{m_{u}}}{\sqrt{m_{u}+m_{T 2}}}\left[1-\frac{c_{T} \pi}{\sqrt{k_{T 2}\left(m_{u}+m_{T 2}\right)}}\right] \sqrt{k_{T 2} m_{u}}
\end{gathered}
$$


where

$=$ static wheel-rail contact force

$[\mathrm{kN}]$

$=$ total dip angle at joint

$=$ train speed

$[\mathrm{m} / \mathrm{s}]$

$=$ linearize Hertzian contact stiffness

$[\mathrm{N} / \mathrm{m}]$

$=$ effective track mass for P1 calculation

$[\mathrm{kg}]$

$=$ unsprung mass

= equivalent track mass for $\mathrm{P} 2$ calculation

$=$ equivalent track stiffness for $\mathrm{P} 2$ calculation $[\mathrm{N} / \mathrm{m}]$

$=$ equivalent track damping for $\mathrm{P} 2$ calculation $[\mathrm{Ns} / \mathrm{m}]$

In addition, an approximate formula is given by Alias (2) as following equation.

$$
P=P_{0}+\lambda 2 \alpha v \sqrt{k m_{u}}
$$

where

$$
\begin{aligned}
& =\text { dimensionless factor depending on track damping }(\leq 1) \\
& =\text { track stiffness } \\
& {[\mathrm{N} / \mathrm{m}]}
\end{aligned}
$$

The above equations indicate that speed and dip angle have most significant influence on dynamic loads at a rail joint. Other properties of track have relatively weak effect on dynamic loads.

\section{Dynamic testing of a steel plate girder railroad bridge}

\subsection{Bridge description}

The subject bridge is a typical steel plate girder railroad bridge located at $290.927 \mathrm{~km}$ from Seoul to Busan. The bridge is $53.4 \mathrm{~m}$ long, and consists of 4

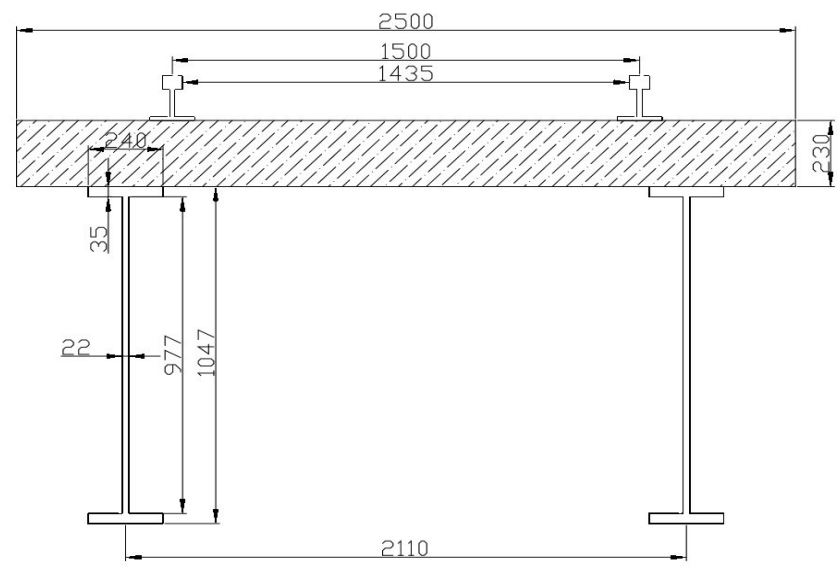

Figure 1: Central section of the mid-span. 
simply supported spans (4@12.10m). The length of each span is $12.10 \mathrm{~m}$. It is composed of two welded plate girders built compositely with wooden sleepers without ballast, as shown in figure 1. Horizontal bracings are installed only on the upper part of the girder and vertical bracings are installed on the left and right point parts and $3.66 \mathrm{~m}$ from each point part to the centre of the girder, so a total of 4 vertical bracings are installed. This is the same for all of the 4 spans. The height of each girder is $1.047 \mathrm{~m}$, and the space between two girders is $2.11 \mathrm{~m}$. As can be seen in figure 2, a rail joint is positioned $1.8 \mathrm{~m}$ apart from the starting point of the 3rd span. It is situated on a sleeper and at the same position on the left and right rails, as shown in figure 3 . The joint has a gap $10 \mathrm{~mm}$ axially, $0.5 \mathrm{~mm}$ vertically and $0.3 \mathrm{~mm}$ horizontally.

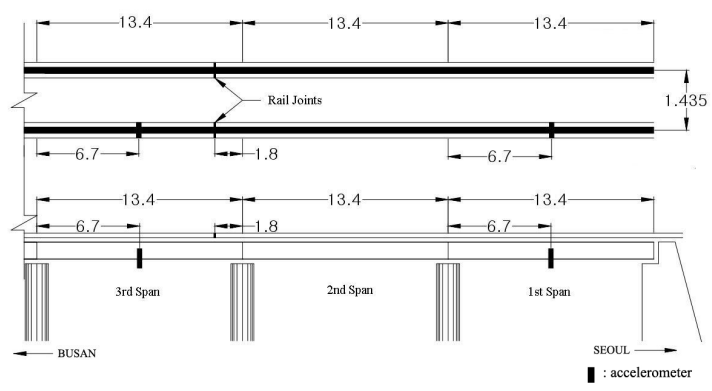

Figure 2: $\quad$ Positions of rail joints and accelerometers.

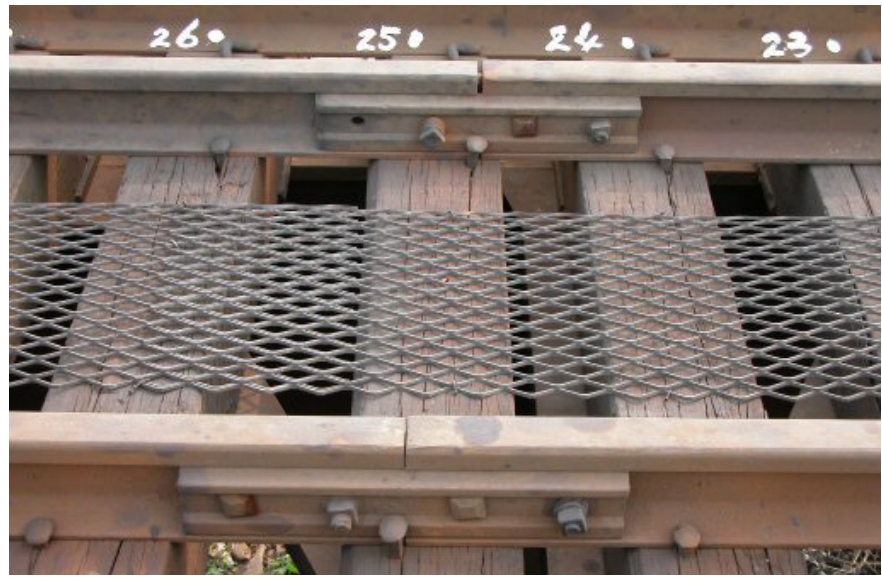

Figure 3: Rail joints. 


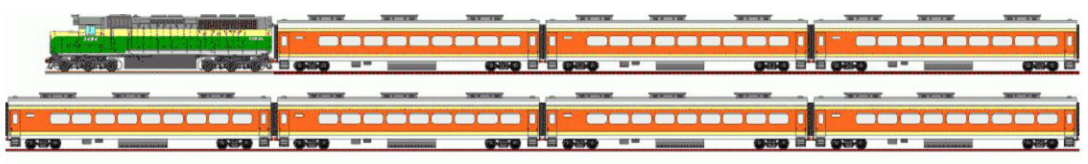

Figure 4: $\quad$ Test train.

\subsection{Train description}

A test train consists of one diesel locomotive and 7 passenger carriages, as shown in figure 4 . It is commonly running on the existing railroad lines in Korea. The diesel locomotive is $20.287 \mathrm{~m}$ long, $3.128 \mathrm{~m}$ wide, and $4.254 \mathrm{~m}$ high. It is composed of two bogies and each bogie has three axles. The load per axle is $215 \mathrm{kN}$. The distance between two axles is $1.854 \mathrm{~m}$, also the distance between the centres of the bogies is $12.497 \mathrm{~m}$. Each of the passenger carriages connected to the diesel locomotive is $23.5 \mathrm{~m}$ long, $3.2 \mathrm{~m}$ wide and $3.7 \mathrm{~m}$ high. It is composed of two bogies and each bogie has two axles. Load per axle is $98 \mathrm{kN}$. The distance between two wheel axles is $2.3 \mathrm{~m}$, and the distance between the centres of the bogie is $15.9 \mathrm{~m}$.

\subsection{Experimental program}

Accelerometers are installed at the bottom flange of centre of 3rd span to acquire bridge response caused by rail joint. For comparison, another accelerometer is installed at the same position of 1 st span which has not rail joint. The accelerometers used in the experiment can measure within the maximum range of $5 \mathrm{G}$. Because this was an experiment on acceleration caused by the operation of an ordinary train, we attached wheel load gauges at $10 \mathrm{~m}$ before entering the 1st span. Signal data were collected during the train passing the subject bridge. A total number of measured data for 45 hours is 30 . All data are filtered through the $100 \mathrm{~Hz}$ low pass technique. This study compare the acceleration response in the 1 st span without a rail joint and the 3rd span with a rail joint to examine the effects of rail joints for each speed band. In measuring, the data sampling rate was set as large as 2000 to prevent the omission of acceleration peaks in the section where the rail joint exists. The regular service train applied the dynamic loading.

\section{Experimental observations}

\subsection{Test results}

As an example, a vertical acceleration time history in the 1st and 3rd span for train running at speed of $122 \mathrm{~km} / \mathrm{hr}$ are as in figure 5 and figure 6 . It shows a significant increase in the acceleration of the span with joints. It also shows that not only instantaneous maximum acceleration but also general acceleration is high. 


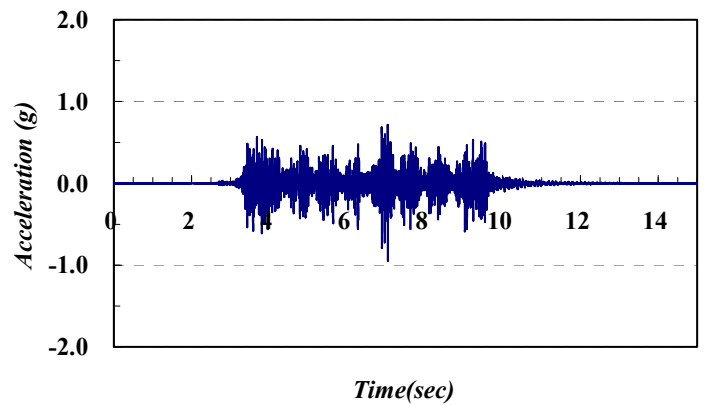

Figure 5: Acceleration time history: first span.

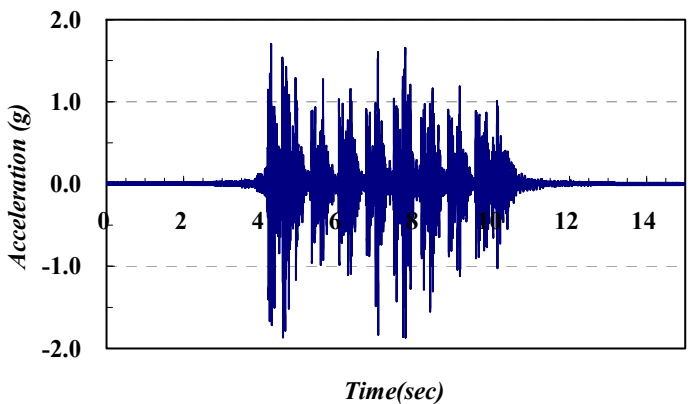

Figure 6: Acceleration time history: third span.

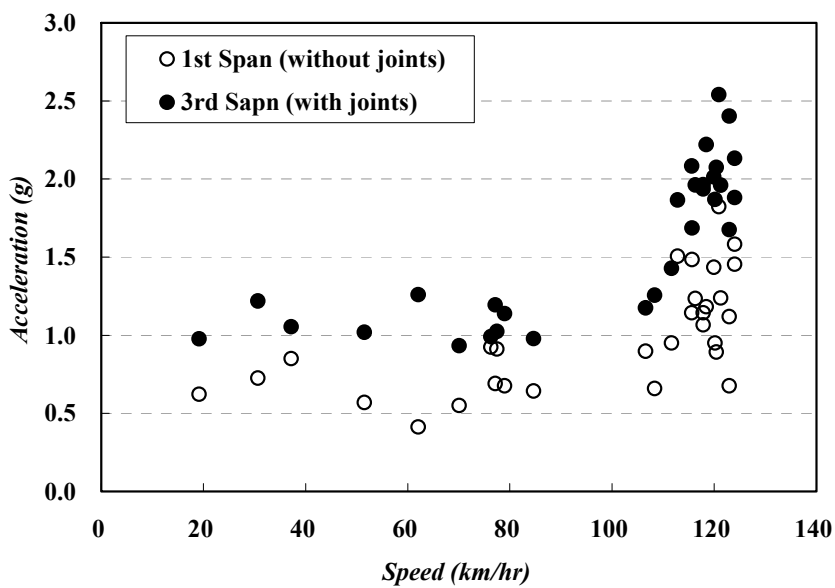

Figure 7: Comparison of PV. 
Table 1: $\quad$ PV, RMS, and DAF value of measured acceleration.

\begin{tabular}{|c|c|c|c|c|c|}
\hline \multirow{2}{*}{$\begin{array}{c}\mathrm{V} \\
(\mathrm{km} / \mathrm{hr})\end{array}$} & \multicolumn{2}{|c|}{$1^{\text {st }}$ Span (without } & \multicolumn{2}{|c|}{$3^{\text {rd }}$ Span (with joints) } & \multirow{2}{*}{ DAF } \\
\hline & Peak(g) & RMS(g) & Peak(g) & RMS(g) & \\
\hline 19.14 & 0.62 & 0.08 & 0.98 & 0.11 & 0.44 \\
\hline 30.66 & 0.73 & 0.08 & 1.22 & 0.10 & 0.22 \\
\hline 37.17 & 0.85 & 0.10 & 1.05 & 0.13 & 0.37 \\
\hline 51.51 & 0.57 & 0.09 & 1.02 & 0.14 & 0.52 \\
\hline 62.06 & 0.41 & 0.11 & 1.26 & 0.27 & 1.48 \\
\hline 70.08 & 0.55 & 0.09 & 0.93 & 0.16 & 0.88 \\
\hline 76.31 & 0.92 & 0.13 & 0.99 & 0.28 & 1.12 \\
\hline 77.12 & 0.69 & 0.11 & 1.19 & 0.19 & 0.78 \\
\hline 77.47 & 0.91 & 0.13 & 1.02 & 0.29 & 1.19 \\
\hline 78.94 & 0.68 & 0.14 & 1.14 & 0.32 & 1.20 \\
\hline 84.61 & 0.64 & 0.12 & 0.98 & 0.21 & 0.78 \\
\hline 106.55 & 0.90 & 0.14 & 1.17 & 0.28 & 1.04 \\
\hline 108.33 & 0.66 & 0.15 & 1.26 & 0.30 & 1.09 \\
\hline 111.65 & 0.95 & 0.18 & 1.43 & 0.32 & 0.74 \\
\hline 112.84 & 1.51 & 0.19 & 1.87 & 0.35 & 0.83 \\
\hline 115.63 & 1.14 & 0.17 & 2.08 & 0.35 & 1.06 \\
\hline 115.64 & 1.48 & 0.20 & 1.69 & 0.39 & 0.98 \\
\hline 116.33 & 1.23 & 0.18 & 1.96 & 0.42 & 1.35 \\
\hline 117.85 & 1.14 & 0.17 & 1.94 & 0.43 & 1.57 \\
\hline 117.85 & 1.07 & 0.17 & 1.96 & 0.40 & 1.36 \\
\hline 118.45 & 1.18 & 0.17 & 2.22 & 0.42 & 1.44 \\
\hline 119.91 & 1.43 & 0.22 & 2.01 & 0.47 & 1.17 \\
\hline 120.16 & 0.95 & 0.16 & 1.87 & 0.39 & 1.49 \\
\hline 120.41 & 0.89 & 0.17 & 2.08 & 0.42 & 1.40 \\
\hline 120.91 & 1.82 & 0.22 & 2.54 & 0.42 & 0.88 \\
\hline 121.28 & 1.24 & 0.19 & 1.96 & 0.40 & 1.15 \\
\hline 122.95 & 0.68 & 0.14 & 2.40 & 0.40 & 1.92 \\
\hline 122.95 & 1.12 & 0.19 & 1.67 & 0.37 & 0.94 \\
\hline 123.99 & 1.58 & 0.22 & 1.88 & 0.40 & 0.85 \\
\hline 123.99 & 1.45 & 0.23 & 2.13 & 0.44 & 0.92 \\
\hline
\end{tabular}


The peak value (PV) of vertical acceleration for each speed band was calculated based on the result of filtering measured acceleration at $100 \mathrm{~Hz}$. The result is presented in table 1 and figure 7 . It is from 1.07 to 3.55 times higher in the span with a rail joint than in that without. The result shows that the instantaneous maximum acceleration of the subject bridge increases significantly by impact load generated by the rail joint.

Root Mean Square (RMS) is an equation to calculate the mean amplitude of signals alternating between plus and minus like vibration. If the representative value is calculated using the maximum amplitude of acceleration signals measured, it may be distort analysis from abnormal signals. RMS can be used as a supplementary indicator for preventing this apprehension. RMS is described by the following equations.

$$
R M S=\sqrt{\frac{1}{N} \sum_{i=1}^{N} a_{i}^{2}}
$$

where

$\mathrm{N} \quad=$ Total number of data

$=$ Each value of acceleration

The RMS of acceleration for each speed band is analyzed based on the result of filtering acceleration measured in each span at $100 \mathrm{~Hz}$. The result is presented in table 1 and figure 8. It is from 1.22 to 2.92 times higher in the span with a rail joint than in that without. This result shows that the mean amplitude of acceleration in the steel plate girder bridge increases significantly by impact load generated by the rail joint

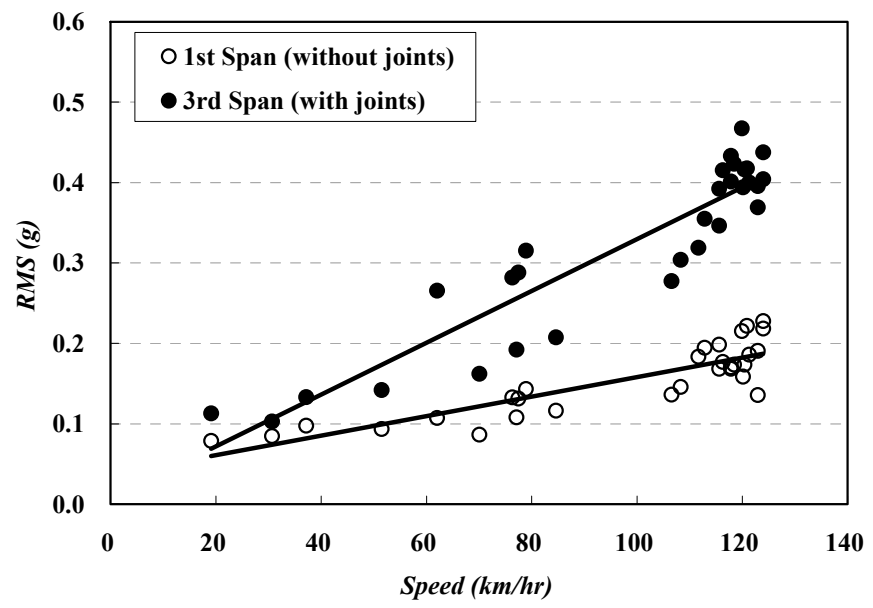

Figure 8: Comparison of RMS. 


\subsection{Discussion of results}

The basis for determining the dynamic factors were provided by Office for Research and Experiments (ORE) specialists committee D23 [6]. When service trains pass over a bridge, the resulting oscillations increase the load by a quantity $\varphi$ made up of the sum of two components. The first component is $\phi^{\prime}$, which is the proportion applicable for a track in perfect geometrical condition. Another components is $\phi^{\prime \prime}$, which is the proportion representing the effect of track irregularities. $\phi^{\prime \prime}$ can be adopted the parameter of comparison with measured result. It is described by the following equation 4. $\varphi$ " of the subject bridge is calculated 0.99 .

$$
\varphi^{\prime \prime}=\frac{1}{100}\left[56 e^{-\left(L_{\phi}{ }^{2} / 100\right)}+50\left(\frac{L_{\phi} n_{0}}{80}-1\right) e^{-\left(L_{\phi}{ }^{2} / 400\right)}\right]
$$

where

$$
\begin{aligned}
& =\text { the effective length (span } \mathrm{L} \text { for a simply supported beam) } \\
& =\text { the first natural frequency of the beam }
\end{aligned}
$$

Also, base on the RMS of the beam at mid-span values of the parameter dynamic amplified factor (DAF) representing the increase in acceleration due to a rail joint can be calculated at different speed by following equation 5 .

where

$$
D A F=\frac{a_{R M S, j o \text { int }}}{a_{R M S, j o \text { int less }}}-1
$$

$=$ RMS acceleration of the span with a rail joint

$=$ RMS acceleration of the span without a rail joint

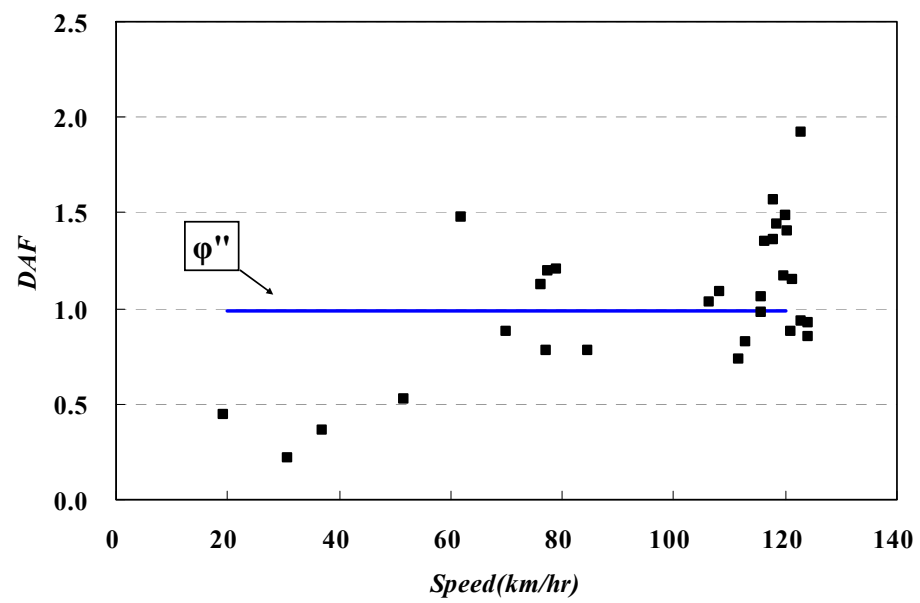

Figure 9: DAF according to speed. 
The calculated DAF from measured data are presented in table 1 and figure 9 with the $\varphi$ ' value. Increasing speed of the test train results in a gradual increase in the DAF. Moreover, the DAF is apt to be larger than $\varphi$ " value in the high speed zone.

\section{Summary and conclusions}

The dynamic behaviour of a railroad bridge is affected by not only the interaction between the bridge and track, but also interaction between the train and the track. This is because train running along the fixed path of the track changes according to the condition of the contact surface. The irregularity of the track surface produces dynamic load. In this condition, the variation of dynamic load is large. In particular, defects or rail joints on the track with discontinuous contact surface results in considerable high impact load. The calculation methods of dynamic load caused by defect of tracks have been studied by Jenkins [1] and Alias [2]. However, there are not sufficient empirical data on what direct effects rail joints have on the behaviour of the bridge. In order to prevent discontinuous operating condition caused by rail joints, most of high-speed railroads adopt continuous welded rail (CWR). However, many of existing bridges using standard-length rails (SLR) have rail joints on them. The steel plate girder bridge is a typical structure of short-span, high-strength and high-frequency bridges. It commonly connected to sleepers without ballast. So, it is most vulnerable to acceleration.

The present study measured the vertical acceleration of bridge with joints and those without in steel plate girder bridges, and examined the effect of rail joints on the dynamic response of bridges through analyzing the PV, RMS and DAF value from measured acceleration.

\section{References}

[1] Jenkins H.H, Stephnson J.E., Clayton G.A., Morland G.W. and Lyon D. The effect for track and vehicle parameters on wheel/rail vertical dynamic forces, Railroad Engineering Journal 3, 1974.

[2] Alias J. Lavoice ferree, Eyrolles, Paris, 1977.

[3] European Rail Research Institute (ERRI) Specialists' Committee D 214. Rail bridges for speeds $>200 \mathrm{~km} / \mathrm{h}$ (Final report $-R P$ 9), ERRI, 1999.

[4] UIC leaflet 776-1R: Loads to be considered in railroad bridge design, 4th edition, France, 1994.

[5] Esveld C. Moder Railway Track, MRT-Productions, Netherlands, 2001.

[6] Office for Research and Experiments (ORE) Question D 23. Determination of Dynamic Force in Bridges (RP 16): Theoretical Study of Dynamic Forces in Bridges, ORE, 1970.

[7] Office for Research and Experiments (ORE) Question D 161.1. Dynamic Effects of 22.5 t Axle Loads on the Track (RP 4), 1987.

[8] L. FrýBA, Dynamics of Railway Bridges, Thomas Telford, 1996. 